\title{
LA QUEMA Y CONFISCACIÓN DE LIBROS COMO PARADIGMA DE CENSURA RELIGIOSA EN LA ANTIGUA ROMA
}

\section{THE BURNING AND CONFISCATION OF BOOKS AS A PARADIGM OF RELIGIOUS CENSORSHIP IN ANCIENT ROME}

\author{
Diego Meseguer González \\ (Universidad de Zaragoza, España) \\ diegoynh@gmail.com
}

Recibido: 27 de mayo 2020 / Aceptado: 18 de agosto 2020

\begin{abstract}
Resumen: Este trabajo tiene como objetivo estudiar el fenómeno de la censura religiosa en la Antigua Roma, haciendo hincapié en los principales episodios que condujeron a la destrucción o cremación de libros mágico-religiosos. Siguiendo un enfoque diacrónico, la primera parte del estudio se centra en las persecuciones llevadas a cabo en época republicana, destinadas a reprimir la difusión de nuevos cultos, evitar su codificación por escrito y mantener el orden tradicional. La segunda parte, en cambio, examina las transformaciones producidas en época imperial y la puesta en práctica de una práctica censora enfocada a proteger los intereses del princeps y eliminar a rivales políticos. Con ello llegaremos a la conclusión de que la censura religiosa constituyó un fenómeno excepcional sujeto circunstancias muy específicas, debido entre otros factores a la ausencia de un órgano institucional especializado en la censura y al peso de la tradición oral sobre la cultura escrita y literaria.
\end{abstract}

Palabras clave: censura, Roma, libros mágico-religiosos, magia

\begin{abstract}
The aim of this paper is to study the phenomenon of religious censorship in the Ancient Rome, making emphasis on the main events that led to the destruction or burning of magic-religious books. From a diachronic perspective, the first part of the study dealts with the persecutions arranged by republican authorities in order to constrain the introduction of new cults, avoid harm coming from its writings and keep safe the
\end{abstract}


traditional order. The second part is concerned with the changes developed at imperial times and the implementation of a censorship policy focused on the protection of princeps and the prosecution of political opponents. Thus, we come to the conclusion that religious censorship was an exceptional issue subject to very specific circumstances, owing to the absence of a specialised censor's office and the influence of oral tradition over written culture.

Keywords: censorship, Rome, magic-religious books, magic

\section{Introducción}

La censura constituye un fenómeno casi tan antiguo como el pensamiento humano, y la Antigua Roma, lejos de ser una excepción, también sufrió sus consecuencias. Como podemos imaginar, la percepción que nosotros mismos tenemos de la censura tiene muy poco que ver con la idea que los romanos se forjaron en torno a ella, si es que alguna vez llegaron a reflexionar sobre el tema. Al carecer de algo parangonable a nuestros derechos fundamentales, los ciudadanos romanos que en el pasado fueron objeto de censura (filósofos, poetas, oradores, etc.) jamás interpretaron esta acción como una coartación de sus derechos y libertades, sino que lo veían, más bien, como una manifestación del poder ostentado por las autoridades, un poder legítimo e incluso necesario. Esta coyuntura, que a nosotros nos puede parecer propia de un régimen dictatorial, puede llevarnos también a pensar que en la Antigua Roma la censura se practicaba con relativa frecuencia; y, en efecto, no estaríamos del todo equivocados si consideramos las numerosas restricciones morales que imperaban en el día a día. Basta pensar, por ejemplo, en la figura del censor, responsable, entre otras funciones, de proteger las viejas costumbres, y cuyo nombre ha dado lugar, precisamente, a nuestro término «censura».

Sin embargo, cuando hablamos de censura literaria y, en particular, de censura religiosa, el panorama cambia considerablemente. Aunque en la Roma de este periodo no existía nada remotamente parecido a la «libertad de prensa» o «libertad de culto», la destrucción de libros de contenido mágico-religioso fue, pese a todo, un fenómeno poco habitual, y, salvo contadas excepciones, los poderes estatales jamás desplegaron una 
política activa de censura. ${ }^{1}$ Por ello, no podemos dejar de preguntarnos, ¿a qué se debe esta aparente tolerancia? ¿Acaso las autoridades romanas no se esforzaron por reprimir ciertos cultos y destruir los libros que transmitían sus enseñanzas?

Para dar una respuesta a estas preguntas, lo primero que debemos hacer es analizar el contexto histórico en el que nos situamos y manejar con rigor las fuentes disponibles. Ello nos lleva a concluir, en una primera aproximación, que la censura literaria se hallaba inevitablemente condicionada por el peso de la tradición oral. El Mundo Antiguo en general, y Roma en particular, conformaba un espacio donde la escritura apenas tenía cabida fuera del ámbito de la administración y el comercio. Solo un porcentaje ínfimo de personas sabía leer y escribir, de ahí que la censura literaria desempeñara un papel tan marginal, sobre todo en el plano religioso. Y es que a estos factores materiales se añaden otros de tipo ideológico, como el carácter aperturista de la religión romana, su flexibilidad en la recepción de nuevos cultos y la ausencia de un libro sagrado que, al modo de las religiones bíblicas, recopilara los principales preceptos religiosos (Woolf, 2012, p. 198). Por consiguiente, si la gran mayoría de la población era analfabeta y si en circunstancias normales los romanos no tenían reparo en compatibilizar su propio culto con el de otros pueblos extranjeros, la destrucción de escritos mágico-religiosos se antoja, a priori, una práctica innecesaria.

Pero todo comenzó a cambiar a partir de época helenística. La irrupción de Alejandría como epicentro cultural dio lugar a una serie de transformaciones que contribuyeron al desarrollo científico y literario de la época, inaugurando un proceso que, unido a la difusión de nuevos cultos orientales, fomentó la codificación por escrito de todo tipo de saberes y experiencias religiosas. El filósofo Platón, cuyo desprecio por la escritura era de sobras conocido, llegó a afirmar con desdén que, hasta los cultos minoritarios, como los misterios órficos, basaban sus sacrificios en un «fárrago de libros» (Pl. Resp. 364d), de los que cabría esperar, además, que se hicieran varias copias. Por otro lado, si bien el corpus formado por los papiros mágicos greco-egipcios data de un periodo

\footnotetext{
${ }^{1}$ De ahora en adelante, cuando hablemos de libros de carácter «mágico-religioso» estaremos refiriéndonos, en un sentido amplio, a todos aquellos escritos que transmitían doctrinas y saberes no sancionados por la autoridad oficial. Hemos optado por esta expresión porque resulta más operativa, a efectos prácticos, que recurrir constantemente a los términos originales, aunque, en aquellos casos que lo precisen, emplearemos el vocabulario técnico latino. Otros autores también se han decantado por un enfoque etic, como es el caso de Daniel C. Sarefield (2004), que prefiere hablar de occult religious texts (p. 30).
} 
posterior en el tiempo, a juzgar por el contenido de algunas recetas y el sincretismo religioso subyacente en ellas, su tradición podría remontarse a esta misma época o incluso a fases anteriores de desarrollo. $\mathrm{Y}$ es que, como anotaron algunos autores, los primeros tratados de magia fueron redactados ya a comienzos del siglo $\mathrm{V}$ a. C. por el persa Ostanes (Plin. NH XXX 8), en analogía a lo que hizo el rey Salomón unos siglos antes al fijar por escrito la manera más eficaz de llevar a cabo un exorcismo (Joseph. AJ VIII 42). En resumen, la especialización del saber en disciplinas más complejas y la expansión por occidente de nuevos cultos exóticos influyeron positivamente en la transmisión por escrito del conocimiento científico y religioso, lo que a su vez favoreció la puesta en marcha de una censura literaria enfocada a la destrucción de estos libros y a la persecución de sus propietarios.

Como eje cultural de esta koiné mediterránea, Roma no fue ajena a todas estas transformaciones. La extraordinaria difusión que alcanzaron en la capital determinadas corrientes filosófico-religiosas, como el estoicismo y el epicureísmo, cristalizó en la redacción de numerosos tratados teóricos a los que muy pocos tenían acceso. Mayor alcance tuvieron, en todo caso, el conjunto de creencias religiosas que, al calor de la conquista, aterrizaron en la capital bajo la forma de nuevos procedimientos rituales. A grandes rasgos, se trataba de ritos y prácticas de cuño griego y oriental con los que la población local satisfacía sus necesidades espirituales, acosta de un culto tradicional incapaz de dar respuesta a situaciones difíciles. Por ejemplo, el judaísmo, cuya presencia en Roma se atestigua ya en el siglo II a. C. (Val. Max. I 3.3), ofrecía a los fieles la salvación personal, la purificación de la culpa y el consuelo ante la adversidad. El culto a Isis y a Cibeles también aseguraba un contacto más estrecho con la divinidad, así como una experiencia espiritual más íntima y exclusiva. Y, por último, a este núcleo doctrinal más o menos centralizado cabría añadir todo el elenco de adivinos, curanderos, exorcistas, intérpretes de sueños, astrólogos, alquimistas y practicantes de magia en general capaces de ofrecer soluciones inmediatas a problemas cotidianos, y cuyas actividades están perfectamente documentadas en las fuentes de la época (Dickie, 2001, pp. 162-175).

Como ya avanzamos anteriormente, la religión tradicional romana se caracterizó desde el principio por ser una religión receptiva ante la llegada de corrientes e influjos extranjeros. De hecho, existían rituales, como la evocatio, basados en acoger a las 
divinidades tutelares de los pueblos enemigos y ofrecerles un santuario en Roma, tal como sucedió, por ejemplo, con Asclepio y la Magna Mater. Ahora bien, esta especie de transigencia religiosa solo era factible en periodos de paz y estabilidad, o lo que es lo mismo, cuando la concordia entre hombres y dioses (pax deorum) se hallaba fuera de peligro. En el momento en que estallaba un conflicto de orden público, como una guerra o una epidemia, las autoridades atribuían tales desgracias a la ruptura de este pacto sagrado y automáticamente cualquier doctrina, creencia o práctica de dudosa procedencia pasaba a considerarse una externa superstitio, y sus escritos un blanco de la censura.

A diferencia de los griegos, lo que más preocupaba a los romanos era garantizar la comunicación con los dioses, y la única forma de conseguirlo era realizando los sacrificios de manera rigurosa y con arreglo a la tradición. En Roma, ningún filósofo habría sido censurado por las mismas razones por las que lo fue Protágoras en Atenas, cuyo tratado Sobre los dioses acabó ardiendo en el ágora junto a varios de sus escritos (Diog. Laert. IX 52). En ellos, Protágoras había manifestado sus dudas respecto a la existencia de los dioses, lo que suponía no solo un ejemplo extremo de impiedad (asebeia), sino un ataque directo a las instituciones sobre las que se sustentaba la polis. En Roma, sin embargo, cuestionar la existencia de las divinidades u ofenderlas no era un delito tan grave, pues como diría el emperador Tiberio, «las injurias hechas a los dioses son de la incumbencia de los dioses» (Tac. Ann. I 73.4). Ignorando estos debates teológicos, la censura estatal trató más bien de silenciar los textos que transmitían nuevas formas de comunicarse con los dioses o, en los peores casos, nuevas técnicas rituales capaces de quebrar la pax deorum y romper el orden establecido.

Conviene admitir, en todo caso, que la censura religiosa se efectuó de manera sumamente esporádica y bajo unas circunstancias muy concretas (Rohmann, 2013, p. 143). Pese a los cambios aducidos más arriba, la memoria y la tradición oral siguieron desempeñando un papel preponderante, en detrimento de una cultura escrita todavía en fase de desarrollo y restringida a círculos muy reducidos. Es esta la razón principal por la que, en contra de lo que se ha sostenido tradicionalmente (Pharr, 1932, p. 280; Speyer, 1981, p. 54), la destrucción de libros mágico-religiosos constituyó un fenómeno aislado y por la que no hubo una legislación efectiva hasta bien entrado el siglo III d. C., como veremos más adelante. 


\section{La censura religiosa en época tardo-republicana}

En este sentido, la primera noticia relativa a la confiscación de escritos mágico-religiosos nos traslada al año 213 a. C., fecha en la que, según narra Tito Livio (XXV 1.12), el Senado ordenó la incautación de «libros de profecías o plegarias» (libros vaticinos precationes) y «copias con ritos de sacrificio» (artem sacrificandi conscriptam). ${ }^{2}$ Para Luis Gil ([1961] 2007), en esta drástica medida se halla el «germen de toda la legislación penal contra la magia, la adivinación y las religiones extrañas» (p. 132), una afirmación quizá algo exagerada si tenemos en cuenta los precedentes, ${ }^{3}$ pero que refleja bien el impacto y la trascendencia del suceso. En cualquier caso, estas medidas no parecen ser el resultado de un plan de censura sistemático y organizado. Desde mi punto de vista, el testimonio de Livio describe más bien un episodio coyuntural, ligado a un contexto muy preciso y a unas circunstancias verdaderamente excepcionales, pues no hay que olvidar que los hechos se enmarcan en plena guerra anibálica y que apenas habían transcurrido tres años desde la derrota en la batalla de Cannas. El caos se había apoderado de la ciudad y en el culmen de la desesperación la población halló consuelo en «prácticas supersticiosas venidas de fuera» (religio et magna ex parte externa, XXV 1.6) auspiciadas por «sacrificadores y adivinos ambulantes» (sacrificuli ac vates, XXV 1.8). Es decir, el miedo y la esperanza, esos sentimientos que, como diría Luciano, «gobiernan despóticamente la vida de los hombres» (Alex. 8), empujaron a las gentes a buscar formas alternativas de comunicarse con los dioses y obtener una respuesta rápida a los problemas del día a día (Caerols, 2006, p. 100).

Las miserias de la guerra ofuscaron la conciencia de la población y la dejaron a merced de una oferta religiosa más variada y atractiva, de suerte que la gran mayoría, muchos de ellos campesinos refugiados de aldeas vecinas, acabó encomendándose a la autoridad de sacerdotes itinerantes y dioses foráneos, y a invadir el foro y otros espacios públicos. ${ }^{4}$ Roma ya había sufrido antes los efectos de una crisis similar, concretamente

\footnotetext{
${ }^{2}$ En ese mismo año, pero al otro lado del mundo, el emperador chino Shi Huandi ordenó la quema de miles de libros (la mayoría vinculados al confucionismo) y castigó a todo aquel que se negara a ello a trabajar como esclavo en la construcción de la Gran Muralla. El año 213 a. C. es considerado por ello una fecha aciaga en la historia de la censura y la libertad de expresión (Hillerbrand, 2006, p. 602).

${ }^{3}$ Como la Ley de las XII Tablas, donde ya se prohibía el uso de encantamientos para atraer las cosechas del vecino (Sen. QNat. IV 7).

${ }^{4} \mathrm{Su}$ actitud recuerda el comportamiento que adoptaron un tiempo después los rodios, que tras largos años de enfrentamiento y como fruto de la desesperación, acabaron por entregarse también a toda clase de sacrificios, oráculos
} 
en el año 428 a. C., cuando, en medio de una larga sequía llegaron a la ciudad «múltiples supersticiones» (multiplex religio) y «nuevos ritos de sacrificio» (novos ritus sacrificandi, Liv. IV 30.9). Pero la situación ahora era mucho más alarmante que en épocas anteriores, ya que, según Livio, estos sacrificadores y adivinos no se conformaban únicamente con «sacar provecho de la ignorancia ajena», sino que, peor aún, ni ofrecían sacrificios ni suplicaban conforme a las «costumbres patrias» (patrio more, XXV 1.7), desafiando la moral tradicional y el pacto sellado con los dioses.

Las autoridades se vieron finalmente obligadas a intervenir y el Senado encomendó al pretor Marco Emilio la misión de poner fin a los disturbios. Finalmente, y por iniciativa del pretor, se tomó la decisión, ejecutada por decreto senatorial, de entregar, antes de las calendas de abril, todos los «libros y escritos» (libros omnes litterasque) que transmitieran prácticas contrarias a la liturgia tradicional, como los libros de plegarias y vaticinios y los tratados con ritos sacrificatorios. Livio salta enseguida a otro tema sin detenerse en las consecuencias que tuvieron tales medidas, por lo que es complicado calibrar su alcance y eficacia. Sea como fuere, lo que sí podemos asegurar es que las confiscaciones del año 213 a. C. marcaron un antes y un después en el respeto a las tradiciones religiosas y que sentaron, además, las bases de una política censora que gozará de un mayor recorrido durante el siglo siguiente.

Como ya hemos insistido en repetidas ocasiones, en la Roma de este periodo la destrucción de libros mágico-religiosos se hallaba sujeta a factores coyunturales, y no a un plan específico orquestado por las autoridades. Partiendo de esta premisa, el único episodio significativo que ilustra un acto de censura religiosa en el siglo II a. C. fue, de nuevo, producto de un hecho accidental: el hallazgo de la tumba de Numa Pompilio. Aunque las fuentes que dan cuenta del suceso pertenecen a épocas muy distintas, todos los autores coinciden más o menos en los detalles principales (Peruzzi, 1973, pp. 107112). El hallazgo tuvo lugar en el año 181 a. C., cuando unos labradores desenterraron por casualidad en el monte Janículo dos arcas de piedra con una inscripción que señalaba la tumba de Numa Pompilio. Cuando abrieron la primera descubrieron que estaba vacía, sin apreciar restos humanos ni ajuares, pero la otra, por el contrario, albergaba en su

y amuletos. Los autores que dan cuenta de la noticia la citan como exponente de desvarío mental e irracionalidad 
interior catorce libros: siete escritos en latín y otros siete en griego. La información sobre su contenido varía según los testimonios, pero, en líneas generales, todos comparten la opinión de que los libros escritos en griego suponían una grave afrenta a la religión tradicional. Hasta tal punto era así que cuando la noticia del hallazgo llegó a oídos del pretor Quinto Petilio, este, habiendo hecho una lectura somera, comunicó al Senado la necesidad de deshacerse inmediatamente de ellos, procediendo a su quema en una asamblea pública presidida por los sacerdotes de la religión tradicional (Liv. XL 29.14). Asistimos, de este modo, a la primera y única cremación de escritos religiosos documentada en todo el periodo republicano, ${ }^{5}$ y a uno de los episodios más representativos de la censura religiosa en la Antigüedad.

Llegados a este punto, la pregunta es obligada: ¿qué es lo que contenían estos libros para causar tal rechazo? Aunque las fuentes distan de ser unánimes (Pena Gimeno, 1979, p. 216), casi todas las versiones de los hechos subrayan que los libros escritos en latín versaban sobre derecho pontificio (septem Latini de iure pontificio) y los griegos sobre asuntos de carácter filosófico-religioso (septem Graeci de disciplina sapientiae), y que, así como los primeros fueron custodiados con sumo celo e interés, los segundos acabaron ardiendo en la hoguera (Liv. XL 29.7; Val. Max. I 1.12; Lactant. Div. inst. I 22.5). Sin duda, la expresión disciplina sapientiae evoca una doctrina filosófica más que un dogma religioso, pero, al mismo tiempo, el hecho de que los libros fueran arrojados al fuego en medio del comitium y a la vista de todo el mundo induce a considerar el acto como una especie de expiación colectiva, tal vez destinada a erradicar una polución religiosa (Herrin, 2009). Esta impresión viene corroborada, a su vez, por la presencia de los victimari, que eran los sacerdotes encargados de inmolar las víctimas en los ritos sacrificiales (Lennon, 2015, 71). Por todo ello, aunque carecemos de pruebas concluyentes que nos permitan discernir con precisión el contenido de estos libros, es probable, o al menos verosímil, que sus páginas transmitieran una mezcla de saberes filosófico-religiosos, y que, tal vez por sus enseñanzas polémicas o por su aroma oriental, fueron vistos por las autoridades como una amenaza contra el orden moral y religioso.

\footnotetext{
${ }^{5}$ Exceptuando la quema de los rollos sagrados de la Torah dictada por Antíoco IV Epífanes en el año 168 a. C. (Forbes, 1936, p. 118).
} 
En torno a esta cuestión, algunos autores llegaron a asegurar que los libros escritos en griego contenían doctrinas del pitagorismo, un movimiento filosófico-religioso que en el siglo II a. C. gozó de gran predicamento entre ciertos sectores de la aristocracia (Plut. Vit. Cat. Mai. 3). Así, el historiador Casio Hemina, coetáneo a los hechos, señala en un fragmento transmitido por Plinio el Viejo que los libros eran de filosofía pitagórica (scripta philosophiae Pythagoricae, NH XIII 86), y en la misma línea se postulan otros analistas de la época, como Calpurnio Pisón (libros Pythagoricos, Plin. NH XIII 87) y Valerio Anciate (pythagoreos fuisse, Liv. XL 29.8). Si diéramos crédito a todas estas afirmaciones, tendríamos, a su vez, que dar respuesta a una serie de incógnitas, como la presunta autenticidad de los libros y la extraña vinculación entre Numa y Pitágoras, que, como era bien sabido, vivieron en épocas muy distantes (Dion. Hal. Ant. Rom. II 59; Liv. I 18.2-3). No obstante, y sin ánimo de ahondar en lo que, a todas luces, parece una clara falsificación literaria (Prowse, 1964, p. 42), lo que a nosotros nos interesa particularmente es remarcar el carácter extraordinario de las medidas adoptadas. La quema de libros responde, una vez más, a un factor coyuntural motivado por un hallazgo casual. Fueran o no escritos pitagóricos, originales o falsificaciones, la decisión de quemarlos no obedece a un plan específico de búsqueda y destrucción, sino que constituye, de nuevo, un mecanismo defensivo con el que las autoridades procuraban preservar el culto tradicional.

Los desórdenes religiosos y morales que la lectura de estos libros podía acarrear eran motivo suficiente para que ardieran en la hoguera (Willi, 1998, p. 146). Como los escritos de profecías y ensalmos confiscados en el 213 a. C., la doctrina pitagórica, o lo que fuera que transmitiesen los siete libros griegos, constituía una desviación de la norma, una transgresión de los cánones tradicionales que, como advierte Valerio Máximo, «podía dañar la religión» $\mathrm{y}$ «alejar las almas de los hombres del respeto a los dioses» (Val. Max. I 1.12). El trasfondo que subyace en la narración de ambos episodios refleja, en suma, un ambiente cultural marcado por la oposición entre dos fuerzas irreconciliables: de un lado, la defensa acérrima de las costumbres de los antepasados, encabezada enérgicamente por figuras como Catón el censor; y de otro, el empuje de nuevas fuerzas de cambio que alentaban la introducción de cultos y creencias extranjeras. Y es en este conflicto entre tradición e innovación donde debemos situar cada uno de los episodios que documentan el ejercicio de la censura religiosa en época republicana. 


\section{La censura religiosa durante el alto-imperio}

Si damos un salto en el tiempo, la actividad censora alcanzó durante el Principado una nueva dimensión. El hundimiento de las instituciones republicanas dio paso a la configuración de un nuevo ordenamiento político articulado en torno a la figura del princeps, que al concentrar en su persona todos los poderes fácticos y religiosos, se convirtió en el principal agente de la censura. De este modo, a partir de mediados del siglo I a. C. asistiremos a una transformación progresiva de las estructuras de poder: la vieja maiestas republicana, que hasta entonces había funcionado como instrumento legal para castigar los delitos de traición contra el Estado, adquirió los tintes de una nueva ley que reprimía con violencia cualquier ofensa realizada al emperador, que además de encarnar la máxima autoridad política, asumió desde tiempos de Augusto la condición de dios (Rudich, 2006, p. 16). Es por ello que, al revestir un carácter sagrado, la censura religiosa se imbricó durante este periodo con la censura política, hasta el punto, como señala L. Gil, de no poder diferenciarse mutuamente ([1961] 2007, p. 164).

Sobre la base de esta nueva plataforma política e institucional, la destrucción de escritos mágico-religiosos siguió siendo, como en tiempos anteriores, un fenómeno excepcional. Aunque las fuentes nos informan con relativa frecuencia sobre expulsiones de astrólogos y magos (Cass. Dio. XLIX 43.5) y sobre la prohibición de determinados cultos, como por ejemplo el isiaco (Cass. Dio. XL 47; LIII 2.4; LIV 6.6), son pocos los testimonios que hacen referencia explícita a la quema o confiscación de libros. Algunos estudiosos, como Moses Finley, se apoyan en el silencio de las fuentes y en la importancia de la tradición oral para sostener que el método más eficaz de efectuar la censura era el destierro en masa, y no la destrucción de escritos (1980, p. 12). Ahora bien, aunque la expulsión de magos y astrólogos fue una dinámica constante en las primeras décadas del Imperio (Cramer, 1954, p. 237), cabe pensar que detrás de todas estas deportaciones se hallaba implícita la voluntad de destruir también los materiales escritos que actuaban como vehículo en la transmisión de sus conocimientos. Por ejemplo, cuando en el año 19 d. C. Tiberio decretó la prohibición del culto a Isis y expulsó a miles de judíos de la capital, ordenó también la quema de sus «vestiduras religiosas» y de todos sus «utensilios de culto» (instrumento), incluyendo, con bastante probabilidad, los libros sagrados (Suet. Tib. 36.1). 
Por otro lado, el impacto psicológico de las guerras civiles alentó el recrudecimiento de determinadas prácticas mágico-religiosas y con ello la proliferación de todo un repertorio de textos y formularios. Son varios los testimonios literarios que dan cuenta de su extraordinaria popularidad, como un pasaje de Horacio en el que se hacen alusión a los «libros de ensalmos» (libros carminum) de una bruja (Epod. XVII 4), o una sátira de Juvenal donde se mencionan los «libros de horóscopos» (libro) y «calendarios gastados» (tritas ephemeridas) de mujeres adivinas (VI 574-578). Semejantes conclusiones podemos extraer del mundo greco-oriental: basta observar la frecuencia con la que Luciano se refiere a estos «libros de hechizos» ( $\beta i \beta \lambda o v \varsigma$, Philop.12; 31) y su destacado papel en la narrativa de ficción, como en la novela de Antonio Diógenes, en la que sus protagonistas, Dercílide y Mantinias, roban al hechicero Paapis sus libros de maldiciones (Phot. Bibl. cod. 166). Mención aparte merece, sin embargo, un pasaje de Pseudo-Focílides en el que se impone la prohibición de preparar pócimas

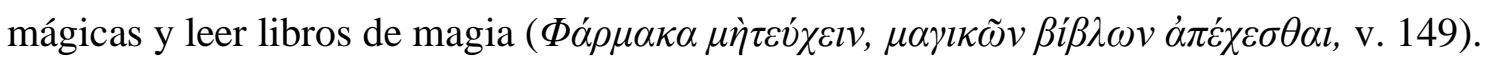
Según recientes investigaciones, el autor de este poema didáctico fue un judío helenizado que vivió en la Alejandría del siglo I d. C. y cuyo propósito era transmitir a sus correligionarios diferentes pautas de comportamiento (Alcalde Martín, 2011, p. 213). El hecho de que prohibiese la consulta de estos libros confirma sin duda su gran difusión no solo entre los griegos, sino también entre la propia comunidad judía, en un escenario que evoca las cremaciones públicas de escritos paganos por parte cristianos en Asia Menor. Véase, por ejemplo, el conocido episodio en el que los cristianos de Éfeso, como gesto de renuncia a sus antiguas creencias paganas, arrojaron al fuego todos sus «libros mágicos» (Hch. 19:19-20).

En definitiva, a la luz de todos estos testimonios literarios podemos concluir que la censura religiosa en época imperial constituyó un epifenómeno de los cambios acontecidos en el plano político y religioso. Una vez más, la angustia y el miedo fueron el telón de fondo de un largo siglo de guerras civiles marcado nuevamente por la exacerbación de prácticas religiosas no sancionadas por las instituciones oficiales. De esta manera, la creciente codificación por escrito de sus enseñanzas y procedimientos rituales puso en alerta a las autoridades del peligro que encarnaban para la estabilidad del régimen. La diferencia, sin embargo, respecto a épocas anteriores estriba en que la 
censura ya no tendrá como objetivo prioritario procurar la cohesión del culto tradicional, sino velar en todo momento por la seguridad del príncipe y su familia.

Así pues, y a falta de una ley específica que condenase la lectura y posesión de libros mágico-religiosos, en el año 12 a. C. Augusto adoptó una medida radical con la que pretendía combatir la difusión de ciertas profecías y vaticinios. ${ }^{6}$ Según Suetonio, el nuevo emperador mandó reunir de todas partes todos los «libros proféticos» (fatidicorum librorum) escritos tanto en griego como en latín -algunos por autores desconocidos y otros por «gente poco digna de crédito»- y quemarlos públicamente. La suma ascendía a un total de dos mil escritos y solo se salvaron los Sibilinos después de ser sometidos a un pequeño expurgo (Aug. 31.1). Los hechos tuvieron lugar poco después de que Augusto reemplazara en el cargo de Pontifex Maximus al difunto Lépido, es decir, siendo la máxima autoridad religiosa. Sin embargo, aunque esta acción se inscribe dentro de un programa enfocado a la restauración del orden moral y religioso (Scheid, 2005, pp. 190191), si analizamos detenidamente el contexto de la situación podremos advertir que detrás de la quema de todos estos libros se oculta una clara motivación política.

Es cierto que el carácter de Augusto era particularmente proclive a eso que nosotros tacharíamos hoy en día de meras supersticiones: su miedo a los rayos era por todos conocido, tanto como su fe ciega en los sueños y prodigios (Suet. Aug. 90-91). Pero de todos los temores que afligían al emperador, ninguno le causaba tanto espanto como el hecho de que se divulgara la fecha de su muerte, pues si alguien daba con dicha información, podía alimentar toda clase de rumores y conspirar para hacerse con el poder. Esta sería, en la línea de lo que postula Frederick H. Cramer (1945, p. 168), la principal motivación subyacente en la quema del año 12 a. C.. Según él, Augusto se estaba precaviendo de una posible conjura, tratando por todos los medios de que la fecha de su muerte, recogida en horóscopos y cartas astrales, no saliera a la luz. Las autoridades imperiales consideraban estos libros oraculares un peligroso instrumento de desestabilización y ya no importaba, como en tiempos pasados, si estaban escritos en griego o en latín. Todos representaban una amenaza en la medida en que todos podían llegar a manos de un enemigo ambicioso y ávido de poder. Y si bien Augusto mostró en

\footnotetext{
${ }^{6}$ Como plantea Fritz Graf, la asociación entre magia y adivinación no se consolidó plenamente hasta época imperial, coincidiendo con la quiebra de los grandes oráculos y santuarios de incubación (1999, pp. 295-296).
} 
ocasiones ciertos síntomas de despreocupación, llegando incluso a acuñar su propio horóscopo en el reverso de las monedas (González García, 2014), sabemos que reprimió con severidad ciertas prácticas adivinatorias, hasta el punto de prohibir a los adivinos profetizar en privado o sobre la muerte de una persona (Cass. Dio. LVI 25.5), pues como indica Tertuliano, solo escudriña en la salud del emperador «aquel que maquina o desea algo contra él o alienta alguna esperanza después» (Tert. Apol. 35.12).

De este modo, la censura religiosa adquirió durante el Principado una connotación política, convirtiéndose en un poderoso instrumento al servicio de los emperadores. Este cambio de tendencia llegó a su máxima expresión durante el reinado de Tiberio, donde el uso abusivo e indiscriminado de la censura desató una larga serie de procesos judiciales, como el celebrado contra Cremucio Cordo (Tac. Ann. IV 34-35), condenado a muerte por elogiar en una de sus obras a los asesinos de César, y Mamerco Escauro (Tac. Ann. VI 29), acusado de difamar presuntamente al emperador en una de sus tragedias (Howley, 2017, pp. 5-7). Pero sin duda, el caso más impactante de todos fue el de Libón Druso, un joven aristócrata que en el año 16 d. C. fue juzgado por el Senado por incurrir en ciertas prácticas prohibidas, como consultar a magos y adivinos e invocar las almas de los muertos (Tac. Ann. II 27-28). Aparte de los testigos que actuaron como delatores, la prueba decisiva que decantó la suerte de Libón fue el hallazgo de un libellus donde estaban escritas, con su puño y letra, «notas siniestras o misteriosas (atrocis vel occultas notas) junto a los nombres de los Césares y senadores» (Tac. Ann II 30). Estos escritos, cuya descripción evoca los textos de las defixiones o tablillas de maldición, sepultaron definitivamente las opciones de Libón, que acabó quitándose la vida días antes de que el Senado pronunciara la sentencia (Shotter, 1972, p. 91).

Episodios como este reflejan a la perfección el viraje que experimentó la censura en tiempos del Principado. Bajo el reinado de los emperadores, la destrucción de escritos mágico-religiosos constituyó, como hemos visto, una forma eficaz de protegerse frente a posibles conjuras, pero también un método rápido y sencillo para deshacerse de adversarios políticos. Según afirman algunos autores, Libón Druso manifestó desde joven una ambición desmedida por el poder, llegando a tramar una «conjuración criminal» contra Tiberio (Vell. Pat. II 130.3) y a «planear una revolución» (Cass. Dio. LVII 15.4). Visto lo visto, pues, no sería descabellado pensar que detrás de todo lo sucedido se oculte 
una intención mucho más profunda, y que el juicio y todos cargos imputados, incluidas las escrituras con signos extraños, formaran parte de un plan orquestado por Tiberio para acabar con él. De ser cierto, estaríamos ante un fenómeno insólito en el ejercicio de la censura religiosa, y es que por vez primera los escritos mágico-religiosos dejarían de ser un blanco u objetivo de los poderes políticos para convertirse en una herramienta a su servicio. De hecho, fuentes tardías documentan la costumbre que tenían ciertos emperadores de enviar agentes a las casas de los condenados para examinar el mobiliario y esconder en secreto pruebas que los incriminen, como encantamientos mágicos y pócimas amatorias (Amm. Marc. XXIX 2.3).

Que Libón Druso fuese inocente o culpable resulta, no obstante, de escaso interés para nosotros. El hecho de que fuera procesado por tales cargos ya es indicativo de que la magia y la adivinación constituían actividades delictivas sancionadas por la ley, como ponen de relieve otros casos similares. ${ }^{7}$ Aun así, y tal como sostiene L. Gil, en época de Tiberio todavía no se llevó a cabo una destrucción sistemática de libros, debido, fundamentalmente, a que el único interés de las autoridades era castigar la mala praxis, y no la scientia o conocimiento técnico de dichas actividades (2007, p. 185). Por ello, habrá que esperar hasta el siglo III d. C. para atisbar las primeras tentativas de regular mediante leyes la lectura y posesión de textos mágico-religiosos.

Como preludio a todo este proceso podemos citar un pasaje de Casio Dion donde se narra el viaje que Septimio Severo realizó a Egipto y las acciones que emprendió en contra de su religión. Según él, «[Septimio] requisó de casi todos los santuarios todos los libros que contenían alguna doctrina secreta ( $\dot{\alpha} \pi o ́ \rho \rho \eta \tau o v)$, y los encerró en el sepulcro de Alejandro Magno» (LXXVI 13.2). Añade Casio Dión que lo hizo para que «nadie en el futuro leyera lo que estaba escrito en ellos», sin aportar ninguna otra pista que nos permita acercarnos al contenido de los textos. Dado el carácter supersticioso de Severo y el interés que desde joven mostró por la astrología, la hipótesis más verosímil apunta a que estos libros egipcios versaban principalmente sobre oráculos y presagios, y que su incautación

\footnotetext{
7 Tácito nos ha transmitido en los Anales abundantes ejemplos de acusaciones de magia promovidas por miembros cercanos a la familia imperial deseosos de eliminar a un adversario político. Véanse, por ejemplo, las acusaciones vertidas contra Lépida (III 22), Numantina (IV 22.3), Claudia Pulcra (IV 52) y Lolia (XII 22.1), que acabaron casi siempre con su exilio o muerte. Otro caso parecido al de Libón Druso, si bien de época tardía, estuvo protagonizado por un joven aristócrata llamado Loliano, que en torno al año $370 \mathrm{~d}$. C. fue acusado por el prefecto Maximino de haber escrito «un libro de artes malignas» (Amm. Marc. XVIII 1.26).
} 
constituía, de nuevo, una maniobra política destinada a impedir que se conozca la fecha de su muerte y se urdieran conspiraciones contra él (Mastrocinque, 2019, p. 304). Como Augusto un tiempo atrás, Severo también fue el precursor de una nueva dinastía, e igual que aquel, también tuvo que hacer frente a numerosas intrigas. Por consiguiente, el deseo de garantizar la continuidad del régimen y frustrar cualquier conato de rebeldía pudo haber justificado, por sí mismo, esta y cada una de las medidas adoptadas en la misma línea, ${ }^{8}$ sentando un modelo de conducta que servirá como fuente de inspiración para futuros emperadores. Sin ir más lejos, casi un siglo después y también con motivo de su visita a Egipto, Diocleciano ordenó quemar todos los tratados de alquimia con la esperanza de que así lograría evitar la fabricación de oro y la financiación de nuevas revueltas y motines (HGF IV 601).

En definitiva, el ascenso de los Severos al poder inauguró una nueva etapa en la evolución de la censura religiosa que culminó, finalmente, con la promulgación de leyes específicas que prohibían la lectura de cierto tipo de libros. Nos referimos, en concreto, a las disposiciones detalladas en el libro V las Sententiae Pauli y en las que se impone la prohibición de leer tratados de adivinación y libros de magia. Así, el capítulo 21, bajo la rúbrica De vaticinatoribus et mathematicis, proclama que todo el mundo «se abstenga no sólo del ejercicio de la adivinación, sino también de su conocimiento teórico (scientia) y de sus libros (libris)»(\$4). Y el capítulo 23, mucho más severo en sus postulados, dispone, al hilo de una serie de medidas destinadas a combatir la hechicería (veneficiis), «que nadie guarde en su casa libros relacionados con las artes mágicas (libros magicae artis)», prescribiendo que, en caso de encontrarse, sean quemados públicamente y sus propietarios castigados. Los que perteneciesen a las clases altas (honestiores) marcharían exiliados a una isla y los más pobres (humiliores) serían ejecutados (§18).

Basándose en la severidad de las condenas y el vocabulario técnico utilizado, James B. Rives sitúa el origen de todas estas medidas a finales del siglo III d. C., aunque, como él mismo argumenta, lo más probable es que se apoyen en una tradición anterior, seguramente en las disquisiciones de Ulpiano sobre los astrólogos o en la ya mencionada

\footnotetext{
${ }^{8}$ Por ejemplo, según Casio Dion, Septimio Severo ordenó pintar sobre las paredes de una de las habitaciones de palacio las principales estrellas y constelaciones del cielo, pero evitó añadir la porción en la que aparecían los astros que rigieron su nacimiento. Con ello evitaba divulgar su horóscopo y que alguien versado en astrología pudiera anticipar la fecha de su muerte (LXXVI 11.1).
} 
incautación de libros por parte de Severo (2003, p. 333). En cualquier caso y como ya hemos adelantado, esta medida legislativa supuso un verdadero punto de inflexión al castigar por primera vez la scientia o conocimiento teórico, y no solo la professio o práctica perniciosa. La repercusión que tuvieron estas leyes a largo plazo puede apreciarse a partir de los numerosos actos de censura religiosa que se sucedieron en época tardía, coincidiendo con el avance del cristianismo y otros movimientos heréticos (Escribano Paño, 2007; Teja, 2008). Sin embargo, su estudio excede los límites de este trabajo, por lo que pasaremos directamente a esbozar las conclusiones finales.

\section{Conclusiones}

Como hemos tratado de exponer en las páginas anteriores, la destrucción de libros de carácter mágico-religioso fue un fenómeno poco corriente en la Antigua Roma, debido, entre otras razones, al peso de la tradición oral y a la ausencia de un órgano institucional especializado en la censura. Aun así, las fuentes documentan varios episodios aislados que, tomados en conjunto, describen una evolución paralela a la represión de estas prácticas y a la persecución de sus seguidores. Así, durante la República el principal objetivo de las autoridades fue combatir los efectos nocivos que podía acarrear en la moral tradicional la introducción de nuevos ritos y creencias extranjeras, como reflejan las confiscaciones del año 213 a. C. o la quema de los libros griegos que aparecieron junto a la tumba de Numa. En cambio, con la llegada del Principado y la configuración de un poder unipersonal, la censura dejó a un lado su interés por asegurar la pax deorum y reprimir los cultos orientales, ya arraigados en la mentalidad popular, para centrarse, más bien, en proteger al emperador de posibles conspiraciones y eliminar con falsas acusaciones a rivales políticos. Sin embargo, pese a todas las acciones emprendidas a lo largo de estos siglos, existen razones para dudar de su verdadero impacto y eficacia. Junto a otros factores ya mencionados, la paradójica atracción que suscitaban los libros prohibidos hizo que muchos continuaran leyéndolos aun después de haber sido censurados, sin olvidar tampoco el extraordinario papel desempeñado por la memoria como baluarte de ideas imposibles de erradicar. Y es que, como afirmó Lactancio un tiempo después, «¿de qué sirvió quemar los libros de Numa cuando aquello por lo cual eran quemados estaba ya en la memoria de las gentes?» (Div. inst. I 22.7). 


\section{Referencias bibliográficas}

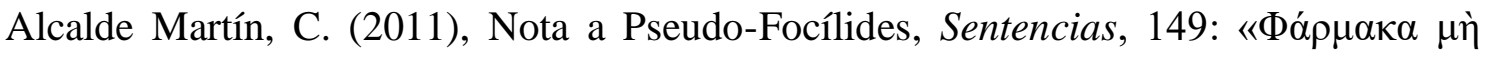

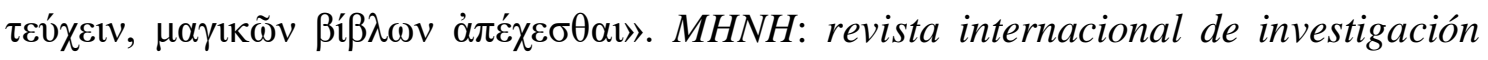
sobre magia y astrología antiguas, $\mathrm{n}^{\mathrm{o}} 11, \quad$ pp. 212-217. https://www.academia.edu/6847838/Ps.-Foc\%C3\%ADlides_Sentencias_149

Caerols, J. J. (2006), Sacrificuli ac vates ceperant hominum mentes (Liv. 25.1.8): religión, miedo y política en Roma. En Urso, G. (Ed.). Terror et pavor. Violenza, intimidazione, clandestinità nel mondo antico. Atti del convegno internazionale, Cividale del Friuli, 2224 settembre 2005 (pp. 89-136). Pisa, Edizioni ETS.

Cramer, F. H. (1945), Bookburning and Censorship in Ancient Rome: A Chapter from the History of Freedom of Speech. Journal of the History of Ideas, n 6(2), pp. 157-196. https://www.jstor.org/stable/2707362?seq=1

Cramer, F. H. (1954), Astrology in Roman Law and politics. Memoirs of the American $\begin{array}{lllll}\text { Philosophical Society, } & \mathrm{n}^{\mathrm{o}} & 37, & \mathrm{pp} & 1-291 .\end{array}$ https://www.jstor.org/stable/pdf/2850091.pdf?seq=1

Dickie, M. (2001). Magic and magicians in the Greco-Roman world. Routledge: Londres, Nueva York.

Escribano Paño, Mª V. (2007), La quema de libros heréticos en el Codex Thedosianus XVI, 5. Ilu. Revista de Ciencias de las Religiones, $\mathrm{n}^{\circ}$ 19, pp. 175-200. http://revistascientificas.filo.uba.ar/index.php/analesHAMM/article/view/2580/2213

Finley, M. y Roussel, M. Cl. (1980), La censure dans l'Antiquité. Revue Historique, $\mathrm{n}^{\circ}$ 263(1), pp.

3-20.

https://www.jstor.org/stable/40953365?seq=1\#metadata_info_tab_contents

Forbes, C. A. (1936), Books for the Burning. Transactions and Proceedings of the American Philological Association, $\mathrm{n}^{\mathrm{o}}$ 67, pp. 114-125. https://www.jstor.org/stable/283231?seq=1

Gil, L. [1961] (2007). La censura en el mundo antiguo. Alianza: Madrid. 
González García, A. (2014), Capricornio y el natalicio de Augusto. Revista Numismática

Hécate, $\quad \mathrm{n}^{\mathrm{o}} \quad 1, \quad \mathrm{pp} . \quad 46-63$.

https://digitum.um.es/digitum/bitstream/10201/49679/1/Capricornio\%20y\%20el\%20nat alicio.pdf

Graf, F. (1999), Magic and divination. En Jordan, D., Montgomery, H. y Thomassen, E. (Eds.). The World of Ancient Magic: papers from the first International Samson Eitrem Seminar at the Norwegian Institute at Athens, 4-8 May 1997 (pp. 283-299). Bergen, Norwegian Institute at Athens.

Herrin, J. (2009), Book-Burning as Purification. En Rousseau, P. y Papoutsakis, M. (Eds.). Transformations of Late Antiquity. Essays for Peter Brown (pp. 205-222). Farnham, Ashgate.

Hillerbrand, H. J. (2006), On Book Burnings and Book Burners: Reflections on the Power (and Powerless) of Ideas. Journal of the American Academy of Religion, $\mathrm{n}^{\mathrm{o}}$ 74(3), pp. 593-614. https://www.jstor.org/stable/4094001?seq=1

Howley, J. A. (2017), Book-Burning and the Uses of Writing in Ancient Rome: Destructive Practice between Literature and Document. Journal of Roman Studies, $\mathrm{n}^{\circ}$ 107, pp. 1-24. https://www.researchgate.net/publication/318323805_BookBurning and the Uses_of_Writing in_Ancient_Rome_Destructive_Practice between Literature_and_Document

Lennon, J. J. (2015), Victimarii in Roman religion and society. Papers of the British School at Rome, n ${ }^{\circ} 83$, pp. 65-89. https://www.jstor.org/stable/24780036?seq=1

Mastrocinque, A. (2019), Septimius Severus and Egyptian Magical Books. Bandue: revista de la Sociedad Española de Ciencias de las Religiones, $\mathrm{n}^{\circ} 11$, pp. 301-307.

Pena Gimeno, Ma. J. (1979), La tumba y los libros de Numa. Faventia, no 1(2), pp. 211230. https://ddd.uab.cat/pub/faventia/02107570v1n2/02107570v1n2p211.pdf

Peruzzi, E. (1973). Origini di Roma. 2, Le lettere. Pàtron: Bolonia. 
Pharr, C. (1932), The interdiction of Magic in Roman Law. Transactions and Proceedings of the American Philological Association, $\mathrm{n}^{\mathrm{o}}$ 62, pp. 269-295. https://www.jstor.org/stable/283219?seq=1

Prowse, K. R. (1964), Numa and the Pythagoreans: A Curious Incident. Greece \& Rome, $\mathrm{n}^{\mathrm{o}}$ 11(1), pp. 36-42. https://www.jstor.org/stable/642630?seq=1

Rives, J. B. (2003), Magic in Roman Law: The Reconstruction of a Crime. Classical $\begin{array}{lllll}\text { Antiquity, } & \mathrm{n}^{\mathrm{o}} & \text { 22(2), } & \text { pp. } & \text { 313-339. }\end{array}$ https://www.academia.edu/26958302/Magic_in_Roman_Law_The_Reconstruction_of a_Crime

Rohmann, D. (2013), Book Burning as conflict management in the Roman Empire (213 BCE - 200 CE). Ancient Society, $\mathrm{n}^{\circ}$ 43, pp. 115-149. https://www.jstor.org/stable/44079972?seq=1

Rudich, V. (2006), Navigating the Uncertain: Literature and Censorship in the Early Roman Empire. Arion: A Journal of Humanities and the Classics, $\mathrm{n}^{\circ} 14(1)$, pp. 7-28. https://www.jstor.org/stable/29737288?seq=1

Sarefield, D. C. (2004). Burning Knowledge: Studies of Book-burning in Ancient Rome. (Tesis de doctorado), Recuperado de https://etd.ohiolink.edu/!etd.send_file?accession=osu1092663236

Scheid, J. (2005), Augustus and Roman religion: continuity, conservatism and innovation. En Galinsky, K (Ed.). The Cambridge Companion to the Age of Augustus (pp. 175-194). Nueva York: Cambridge University Press.

Shotter, D. C. (1972), The trial of M. Scribonius Libo Drusus. Historia: Zeitschrift für

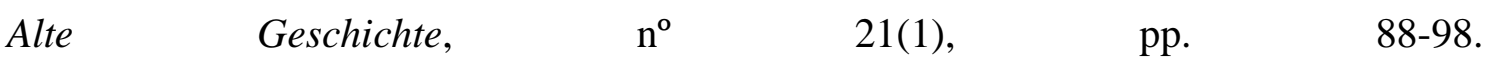
https://www.jstor.org/stable/4435247?origin=JSTOR-pdf\&seq=1

Speyer, W. (1981). Büchervernichtung und Zensur des Geistesbei Christen Heiden, Juden. Kohlhammer: Stuttgart. 


\section{REVISTA IBEROAMERICANA, ACADÉMICO CIENTÍFICA DE HUMANIDADES, ARTE Y}

CULTURA (ISSN: ISSN: 2530-6014), NÚM. 8 (SEPTIEMBRE 2020)

Teja, R. (2008), La quema de libros de magia como forma de represión religiosa y política en el Imperio cristiano. Bandue: revista de la Sociedad Española de Ciencias de las Religiones, $\mathrm{n}^{\circ} 2$, pp. 73-100.

Willi, A. (1998), Numa's dangerous books: the exegetic history of a Roman forgery. Museum Helveticum: schweizerische Zeitschrift für klassische Altertums wissenschaft, $\mathrm{n}^{\mathrm{o}}$ 55, pp. 139-172. https://www.jstor.org/stable/pdf/24821063.pdf?seq=1

Woolf, G. (2012), Reading and religion in Rome. En Rüpke, J. y Spickermann, W. (Eds.). Reflections on Religious Individuality. Graeco-Roman and Judaeo-Christian Texts and Practices (pp. 193-208). Berlín: De Gruyter. 